\title{
ОБЗОРЫ
}

\section{Влияние корпоративных конфликтов на эффективность управления и стоимость компании: обзор теории и эмпирических свидетельств}

\author{
Щукина Л.Г. ${ }^{21}$
}

Корпоративные конфликты оказывают влияние на эффективность управления персоналом любого уровня: совета директоров и топ-менеджмента, менеджмента среднего и линейного уровней, не руководящих работников. Это объясняется существованием агентской проблемы во взаимоотномениях как между собственниками и менеджерами, так и между менеджерами $u$ ux подчиненными. $C$ повышением эффрективности управления персоналом увеличивается стоимость компании $u$ благосостояние ее акционеров: для этого изели наемных работников должны совпадать с интересами собственников, что является базовой предпосылкой многих экономических моделей. Наличие агентской проблемы исключает выполнение этой предпосылки, и именно поэтому современные компании нуждаются в системе менеджмента и корпоративного управления.

Вероятность возникновения корпоративных конфликтов заставляет заранее искать возможности согласования различных позиций, и в этом контексте корпоративный конфликт - это способ развития и совершенствования корпоративного управления. С другой стороны, разрешение корпоративных конфликтов требует ресурсов, которые отвлекаются, в том числе и от повышения эффективности управления предприятием, дальнейтего развития бизнеса и увеличения акционерного капитала.

Вопрос о взаимосвязи корпоративных конфликтов и качества внутрифирменного менеджмента чрезвычайно актуален для России, где продолжсаются процессы реструктуризации компаний, зачастую эти прочессы протекают одновременно со сменой собственника. В представленной статье рассмотрен ряд моделей из разных отраслей экономической теории, которые описывают взаимосвязь между действиями менеджеров компаний - участнии корпоративных конфликтов, между возможностью и издержками мониторинга результатов работы менеджеров, между эффективностью стимулируюших контрактов и благосостоянием акиионеров.

Модели оценки эффективности наемных работников позволяют сделать выводы о том, насколько важно бывает порой для менеджмента избавиться от контроля владельцев бизнеса, а для собственников, наоборот, сделать этот контроль и оченку качества работы управляющих более эффективными. Компенсаџии менеджерам, основанные на стоимости ценных бумаг компании, безусловно, снижают стимульь к оппортунистическому поведению менеджеров, а степень доверия собственников информации, поставляемой рынком и собственным менеджментом, является главным стимулом для отложенных выплат управляющим.

JEL: G34, G35, J21, J24, J31, J32, J33, J54, M51, M52

Ключевые слова: корпоративные конфликты, агентская проблема, эффективность

\footnotetext{
${ }^{21}$ Аспирант кафедры экономического анализа организаций и рынков факультета экономики ГУ ВШЭ, ведущий инженер отдела ценообразования и сметных расчетов по ремонту скважин аппарата управления Пермского филиала ООО «Буровая компании «Евразия».
} 
управления, стоимость компании, максимизаџия благосостояния акиионеров, гипотеза неэффективности рынка, гипотеза неэффективности менеджмента, модели оценки эффрективности наемных работников, качество труда, сигналы на рынке труда, стимульк к образованию и повышению квалификачии, заработная плата, конкуренция за человеческие ресурсы, советы директоров, слияния и поглощения, компенсачии топ-менеджерам, оппортунистическое поведение менеджеров, мотивация и поощрение сотрудников.

\section{Введение}

Бизнес постоянно претерпевает изменения. При любых изменениях может возникать корпоративный конфликт, в связи с тем, что контроль над собственностью переходит от одних к другим, не только как право владеть, но и как право управлять. В данном контексте под корпоративным конфликтом понимается не только явный конфликт, принимающий форму судебных или иных споров, но и противоречия, которые могут оставаться латентными, воздействуя, тем не менее, на внутреннюю систему управления.

Корпоративные конфликты оказывают определенное влияние на эффективность управления персоналом любого уровня: совета директоров и топ-менеджмента, менеджмента среднего и линейного уровней, не руководящих работников. Это объясняется существованием агентской проблемы во взаимоотношениях как между собственниками и менеджерами, так и между менеджерами и их подчиненными. С повышением эффективности управления персоналом увеличивается стоимость компании и благосостояние ее акционеров: для этого цели наемных работников должны совпадать с интересами собственников, что является базовой предпосылкой многих экономических моделей ${ }^{22}$. В реальной жизни данное условие выполняется крайне редко, и именно поэтому современные компании нуждаются в системе менеджмента и корпоративного управления. Существуют различные схемы оплаты труда и премирования работников, позволяющие отчасти нивелировать агентскую проблему. Кроме того, сам рынок корпоративного контроля (как и другие внешние инструменты корпоративного управления) является способом стимулирования менеджеров к более эффективной работе.

В представленной статье мы рассмотрим ряд моделей из разных отраслей экономической теории, которые описывают взаимосвязь между действиями менеджеров, возможностью мониторинга результатов их работы и благосостоянием акционеров.

Во-первых, это модели, отражающие воздействие внутрифирменного менеджмента на эффективность слияний, поглощений и других форм корпоративной реструктуризации. Вовторых, это модели, объясняющие некоторые особенности агентского конфликта и связанные с проблемой оценки эффективности действий наемных работников вообще и управляющих работников в частности. В-третьих, это модели различных способов эффективной организации стимулирования менеджеров к тому, чтобы действовать в интересах акционеров.

При анализе моделей нас будут интересовать несколько вопросов. Во-первых, содержание базовой теоретической конструкции модели. Во-вторых, опыт использования данной теоретической конструкции для объяснения феноменов хозяйственной практики в разных странах мира. В-третьих, подходы к эмпирическому тестированию предсказаний моделей и результаты такого тестирования. В итоге мы сможем обобщить выводы экономической теории о связи между корпоративными конфликтами и развитием внутрифирменного управления.

\footnotetext{
22 Например, модели влияния структуры капитала на рыночную оценку фирмы Миллера-Модильяни [Modigliani, Miller, 1958], сигнальная модель Майерса-Майлуфа [Myers, Majluf, 1984].
} 


\section{Эффективность действий менеджмента и результаты слияний}

В работе Шлайфера и Вишны 2001 г. предложена классификация существующих теорий оценки эффективности сделок на рынке корпоративного контроля: теории, основанные на гипотезе неэффективности рынка, и теории, основанные на гипотезе неэффективности менеджмента [Shleifer, Vishny, 2001].

В соответствии с первой гипотезой, рынок неэффективен и недостаточно корректно оценивает компанию-покупателя, целевую компанию и компанию, образующуюся в результате сделки, а менеджеры, наоборот, эффективны и рациональны. Менеджеры знают, что рынок неэффективен, и извлекают из этого выгоды. Компания-покупатель чаще всего находится под контролем мажоритарных акционеров или менеджеров, которые слишком амбициозны. В результате слияния снижается эффективный горизонт планирования менеджеров целевой компании. Это происходит потому, что долгосрочно ориентированные менеджеры целевой компании получают возможность продать имеющиеся у них переоцененные акции или опционы и получить деньги. Менеджеры компании-покупателя, в свою очередь, получают возможность увеличить стоимость своей компании и благосостояние своих акционеров. Эмпирическое подтверждение этой гипотезе можно найти и в более ранних работах Шлайфера и Вишны [Shleifer, Vishny, 1988], а также в работах Бэйкера и Вэрглера [Baker, Wurgler, 2000, 2002], Морка [Morck, Shleifer, Vishny, 1988], Стайна [Stein, 1988, 1989, 1995] и других исследователей.

Майерс и Майлуф [Myers, Majluf, 1984] предложили модель неблагоприятного отбора среди фирм на рынке корпоративного контроля, также основанную на гипотезе неэффективности рынка. В новой отрасли большинство фирм могут показаться одинаковыми на взгляд недостаточно информированного инвестора, в то время как инсайдеры могут обладать более полной и более правдивой информацией о будущей доходности таких фирм. Фирмы с доходностью ниже средней будут переоценены рынком, на котором работают не слишком осведомленные инвесторы. Соответственно, для финансирования новых проектов (например, слияний и поглощений) фирмы выберут дополнительную эмиссию акций, а не размещение облигационных займов. Фирмы с уровнем доходности выше среднего будут недооценены, и, соответственно, выпуск новых акций для них может показаться слишком дорогим. В условиях асимметрии информации фирмы «низкого качества» (с низкой оценкой будущей доходности) имеют тенденцию более быстрого роста, чем фирмы «высокого качества», а это приведет к тому, что на рынке будут доминировать «лимоны» (разросшиеся гиганты с неэффективной бюрократической системой управления) [Myers, Majluf, 1984].

Вторая гипотеза предполагает, что рынок эффективен, а менеджеры компаниипокупателя, наоборот, неэффективны и думают, что они могут оценить целевую компанию лучше, чем рынок [Roll, 1986]. Управленцы могут переплатить целевой компании, если переоценивают свои управленческие способности и предполагают, что смогут таким образом наладить производство в целевой компании, чтобы она приносила прибыль. Подтверждение данной гипотезе можно найти в исследованиях Дженсена [Jensen, 1984, 1986], Мартина и Макконнэлла [Martin, McConnell, 1991], Манна [Manne, 1965], Шлайфера и Саммерса [Shleifer, Summers, 1988].

Следуя логике работы Дженсена [Jensen, 1984], менеджеры могут участвовать в неэффективных слияниях и поглощениях, если это позволит увеличить размеры их компании, так как престиж и вознаграждение менеджеров зависит от размеров фирмы. Кроме того, в больших компаниях, имеющих сложную структуру, способность акционеров контролировать действия менеджеров снижается. Желание менеджеров уйти от контроля собственников является одним из сильнейших мотивов для участия в различных корпоративных конфликтах, не только в слияниях и поглощениях, но и в дроблении бизнеса, выделении и реорганизации / реструктуризации активов компании. Для того чтобы 
оптимизировать механизмы контроля и стимулирования менеджмента и свести к минимуму связанные с этим издержки, собственники должны иметь возможность корректно оценить эффективность наемных работников.

\section{Проблема оценки эффективности наемных работников}

Оценка производительности работника, качества и эффективности его труда является одной из наиболее важных проблем менеджмента, поскольку мы не можем управлять тем, чего не можем оценить, и не можем улучшить то, чего не можем оценить. В прежнем мире работы, когда сотрудник увольнялся, компании теряли пару рук и ног. Когда сегодня люди уходят из организаций, они уносят с собой ценные знания и информацию - о бизнеспроцессах, заказчиках, стратегиях и проектах фирмы. Компании, желающие преуспеть, не могут полагаться на технологии, которые меняются и совершенствуются постоянно. Они должны разработать систему выбора специалистов, которая позволит привлечь лучших и талантливых, сориентировать их в нужном направлении, поощрить за достигнутые результаты, научить терпимо относиться к переменам в организации и принимать их. Внутри компаний на смену старому «общественному договору», когда работодатели искали сотрудников, которые заполнят существующие вакансии и будут выполнять определенные функции, приходит новая концепция: работодатели вкладывают средства в сотрудников, которые увеличивают стоимость их бизнеса, что позволит стимулировать работников к достижению более высокого уровня эффективности работы. Вот почему так важен первоначальный отбор работников при их приеме в компанию.

Существуют различные модели оценки эффективности наемных работников. Мы рассматриваем те из них, которые основаны на предположении о том, что истинный уровень производительности работника оценить невозможно, поэтому единственным способом достоверной оценки является интерпретация сигналов в рамках разделяющего равновесия Байеса-Нэша. В соответствии с предпосылками о правдивости сигналов на рынке труда модели можно сгруппировать следующим образом:

1) модели ex ante, основанные на предпосылке о правдивости сигналов (модели Спенса $^{23}$, Шапиро и Стиглица, Райли, Ланга и Кроппа, Бедарда);

2) модели ex post, основанные либо на предпосылке о том, что сигналы не являются правдивыми (модель конкуренции за талантливых работников Волдмана);

3) либо о том, что сигналы правдивы лишь наполовину ${ }^{24}$ (модель увольнений Гиббонса и Каца).

Спенс не ставил себе целью изучение рынка труда, взаимоотношений между работодателем и наемным работником, его исследования были посвящены теории сигналов и перераспределению информации на рынках, рынок труда использовался им лишь как показательный пример, таким образом, многие особенности и характерные черты взаимоотношений работодателей и работников были упущены. Тем не менее именно эти простейшие модели дали возможность сформировать теоретическую базу для анализа эффективности работы менеджмента. В модели Шапиро и Стиглица предполагается, что работодатель имеет возможность отследить, насколько эффективны его работники. Работника, пойманного на недобросовестном выполнении своих обязанностей, увольняют, и всю оставшуюся жизнь, независимо от того, устроится ли он на работу в другую фирму, или

\footnotetext{
${ }^{23}$ Простейшая модель сигналов на рынке труда; модель с 2мя группами работников, в которой образование выступает как сигнал; модель с сигналами и отбором; общая временная модель [Spence, 2001].

24 Например, прежний работодатель точно знает, что уволенные им работники эффективны (или неэффективны), а новый может лишь строить догадки, исходя из новостей о том, что люди попали под сокращение или идет реорганизация предприятия и новый хозяин желает сменить весь менеджмент, начиная с линейного.
} 
откроет собственное дело, он будет вынужден работать за резервную заработную плату ${ }^{25}$, уровень которой ниже, чем он мог бы получать на своей прежней работе [Shapiro, Stiglitz, 1984]. Райли [Riley, 1979] сделал первую попытку эмпирически протестировать модель сигналов на рынке труда, предложенную Спенсом [Spence, 2001]. Его идея заключалась в том, что сигналы наиболее эффективны в тех отраслях, где трудно оценить качество труда. В таких отраслях заработная плата и образование должны иметь сильную взаимосвязь с карьерой, в то время как связь будет намного слабее в тех отраслях, где эффективность труда легче оценить. Со временем работодатели лучше узнают своих работников и даже в тех отраслях, где изначально было сложно отследить, насколько хорошо работники выполняют свои обязанности, связь между заработной платой, эффективностью труда, образованием и карьерой становится слабее. Позднее модель Спенса была протестирована Лангом, Кроппом [Lang, Kropp, 1986] и Бедардом [Bedard, 2001], и оба исследования подтвердили ее состоятельность.

Фарбер и Гиббонс [Farber, Gibbons, 1996] предложили дальнейший вариант развития модели Спенса, дав возможность работодателю получать информацию об эффективности труда работника, изучая его предыдущую карьеру. Их модель предполагает, что образование не влияет на уровень заработной платы (независимо от того, сколько времени человек является агентом рынка труда), а другие неизмеримые или трудно измеримые факторы, свидетельствующие об эффективности труда работника, со временем приводят к увеличению заработной платы.

Волдман [Waldman, 1984] рассматривал ситуацию, в которой фирмы конкурируют между собой за талантливых работников. В связи с тем что ни один работодатель не хочет потерять хорошего работника, он никогда не будет поручать этому работнику заданий, которые позволили бы тому в достаточной степени проявить себя как профессионала. Выполнение ответственных заданий будет рассматриваться как сигнал для конкурентов о том, что перед ними отличный специалист, в то время как в действительности эти задания будут выполняться вполне заурядными работниками, а настоящие «звезды» будут оставаться в тени. Такая стратегия может быть оптимальной для отдельной фирмы в условиях конкуренции за человеческие ресурсы, но итогом подобного поведения большого количества фирм, безусловно, является неэффективное и нерациональное использование человеческого капитала.

Бернар [Bernhardt, 1995] развивает эти идеи в собственном анализе продвижения по карьерной лестнице, объясняя, почему люди, имеющие более низкий уровень образования, чаще бывают рекомендованы на более высокие посты и почему они порой демонстрируют необыкновенную работоспособность. Работодатель, который хочет скрыть от своих конкурентов информацию о собственных работниках, имеет достаточно стимулов для того, чтобы не продвигать по службе специалистов, имеющих хорошее образование. Таким образом, для того, чтобы оправдать свой недостаточный уровень профессионализма и свое несправедливое повышение в должности, работник вынужден работать с гораздо большим усердием, чем его более профессиональный коллега. Мильгром и Oстер [Milgrom, Oster, 1987] отмечают, что подобная дискриминация ведет к неэффективности социальных институтов: работники назначаются на те должности, которые не соответствуют их уровню образования и профессионализма, кроме того, работники не имеют достаточных стимулов к повышению квалификации и обучению.

В своем эмпирическом анализе увольнений на рынке труда с асимметричной информацией Гиббонс и Кац [Gibbons, Katz, 1991] тестировали значимость неблагоприятного отбора и сигналов. Если фирмы легко могут определить, кого из работников следует уволить, то другие агенты рынка труда будут считать увольнение сигналом о том, что это плохой работник («лимон»), что его производительность ниже

\footnotetext{
${ }^{25}$ По определению резервная ставка заработной платы — это уровень заработной платы, при котором работник безразличен в своем выборе между тем, чтобы работать и не работать [Shapiro, Stiglitz, 1984]. 
среднего уровня. Работники, которые выглядят подобным же образом в свете оценки собственной трудоспособности, но лишились работы, например, по причине того, что закрылась их фирма, легче смогут найти себе новую работу с более высокой заработной платой. Основываясь на исследовании большой выборки уволенных работников, Гиббонс и Кац нашли подтверждение этой гипотезе.

Мы рассмотрели результаты различных исследований, показывающих, каким образом связаны между собой действия менеджмента корпораций и результаты сделок на рынке корпоративного контроля и то, насколько важно бывает порой для менеджмента избавиться от контроля владельцев бизнеса, а для собственников, наоборот, сделать этот контроль и оценку качества работы управляющих более эффективными. Точно так же и для самих топменеджеров необходимо иметь возможность максимально корректно оценить деятельность своих подчиненных.

Приведенные в статье примеры моделей оценки эффективности наемных работников позволяют сделать вывод о том, что выбор и качество управленческих решений зачастую обусловлены не только и не столько профессиональной подготовкой менеджмента компании, сколько комплексом мотиваций, на основе которых они принимаются. Далее мне хотелось бы более подробно остановиться на проблеме влияния действий советов директоров (как самого высокого уровня управляющих компанией) на благосостояние владельцев компаний, принимающих участие в сделке, при принятии решений о слияниях и поглощениях.

\section{Влияние эффективности советов директоров на благосостояние владельцев компаний, принимающих участие в слияниях и поглощениях}

В связи с тем, что решение об участии в поглощении другой компании принимает совет директоров, то, каким является этот совет, напрямую связано с результатами предпринимаемых действий. В своем исследовании братья Константину изучили изменение благосостояния акционеров компаний-покупателей, принимавших участие в 185 сделках на рынке корпоративного контроля Великобритании в течение периода с 1990-го по 1997 г., и сделали попытку объяснить эти изменения различиями в структуре советов директоров компании-покупателя и целевой фирмы [Constantinou, Constantinou, 2003].

Обычно в англо-американской системе корпоративного управления совет директоров компании включает несколько топ-менеджеров фирмы и несколько директоров-аутсайдеров. Исполнительные директора, как постоянные работники фирмы, предоставляют совету всю существенную информацию о деятельности компании. Неисполнительные директора больше вовлечены в процесс стратегического планирования [Fama, 1980] и в сравнении с исполнительными директорами имеют больше стимулов для того, чтобы более профессионально представлять интересы акционеров и быть более объективными в оценке издержек и выгод акционеров при принятии решения о поглощении [Cotter, Shivdasani, Zenner, 1997]. Таким образом, можно сделать вывод о том, что чем больше неисполнительных директоров входит в совет, тем выше вероятность выгодного для акционеров (и компании-покупателя, и целевой компании) слияния / поглощения, поскольку неисполнительные директора с большей вероятностью будут принимать решения, которые позволят максимизировать благосостояние акционеров. Исследования подтверждают, что неисполнительные директора представляют интересы акционеров через усиление мониторинга и поэтому эффективные менеджеры предпочитают советы директоров с большим количеством неисполнительных директоров.

Важно обратить внимание на тот факт, что неисполнительные директора могут принимать участие одновременно в советах директоров разных компаний, поскольку они не являются постоянными работниками одной фирмы. Соответственно, они накапливают определенный опыт и знания, которые могут быть весьма полезны для фирмы при оценке предстоящих слияний и поглощений [Constantinou, Constantinou, 2003]. Поль Ло отмечает, 
что участие в работе совета независимых директоров служит гарантией принятия эффективных решений [Пирогов, Урюпин, 2007]. Фама и Дженсен [Fama, Jensen, 1983a, 1983b] утверждают, что неисполнительные директора, которые принимают участие сразу в нескольких советах, имеют больше стимулов для того, чтобы способствовать принятию корпоративных решений, позволяющих удовлетворить интересы всех акционеров, как если бы они сделали инвестиции в специфический актив - свою репутацию, как репутацию экспертов в области принятия корпоративных решений. Несмотря на то что противостояние поглощению может и не быть столь опасным для их позиции в совете директоров (хоть компании-покупателя, хоть целевой компании), издержки, связанные с принятием невыгодного для акционеров решения могут оказаться намного больше, поскольку они приведут к ухудшению репутации менеджеров. С другой стороны, чем в большем количестве компаний топ-менеджер является членом совета директоров, тем меньше времени он будет уделять каждой отдельно взятой компании и тем менее ценным становится его вклад в бизнес компании. Следовательно, когда неисполнительные директора являются членами советов в небольшом количестве компаний, это повышает их эффективность как управленцев. Когда же они принимают участие в огромном количестве советов директоров, их эффективность падает [Constantinou, Constantinou, 2003].

Шивдасани [Shivdasani, 1993] пришел к выводу, что дополнительное членство в советах директоров других компаний снижает вероятность недружественных поглощений, что подтверждает гипотезу о контролирующей роли неисполнительных директоров. К сожалению, не накоплено достаточного количества эмпирических данных, которые подтверждали или опровергали бы существование взаимосвязи между участием в нескольких советах директоров и результатами слияний и поглощений. О'Салливан [O'Sullivan, 2000] пришел к выводу о том, что менеджеры вряд ли будут принимать участие сразу в нескольких советах директоров, если во главу угла они ставят достижение собственных целей за счет средств акционеров компании, в то время как более востребованные неисполнительные директора являются более обеспеченными людьми и гораздо менее амбициозными управленцами [Constantinou, Constantinou, 2003].

Другой важной характеристикой, связанной с качеством и эффективностью управления бизнесом, является количество членов совета директоров. Липтон и Лош в своей работе пришли к заключению о том, что количество членов совета директоров не должно превышать 10 человек. Они считают, что именно такое количество позволит директорам сработаться, даст им возможность принимать участие во всех дискуссиях и эффективно вести переговоры. Основная идея их работы заключается в том, что когда совет директоров состоит из большого количества членов, не все из них имеют возможность выразить свое мнение и полностью изложить свои аргументы за то время, что отведено на встречи. Также и Дженсен в своем исследовании пришел к выводу о том, что, когда советы состоят из 7-8 или менее членов, они с меньшей вероятностью будут действовать эффективно и генеральному исполнительному директору будет легче захватить власть в свои руки и принимать решения единолично [Constantinou, Constantinou, 2003].

Ермак [Yermack, 1996] также придерживается точки зрения о том, что сокращение количества членов совета директоров приводит компании к кризисным ситуациям: небольшие советы директоров менее эффективны и дают больше возможностей генеральным исполнительным директорам единолично управлять советом, поскольку директора боятся потерять свои должности и вознаграждения. Это подтверждают и результаты исследований Кини и др., которые пришли к выводу о том, что количество членов совета становится меньше после того, как осуществляются поглощения недооцененных компаний. Положительный эффект от большого количества членов совета директоров можно рассматривать сквозь призму проблем, связанных с асимметрией информации между генеральным исполнительным директором и советом директоров, особенностями переговорных процессов и принятия решений в целом. С другой стороны, в больших советах директоров больше экспертных оценок, так как у каждого из членов совета 
больше собственных уникальных знаний, немаловажно и то, что обмен мнениями и более широкое освещение различных аспектов позволяет сформировать более взвешенную корпоративную стратегию [Constantinou, Constantinou, 2003].

Количество акций, находящихся во владении у членов совета директоров, является еще одной характеристикой, напрямую связанной с качеством управления бизнесом. С увеличением доли акций, принадлежащей менеджерам, степень совпадения интересов акционеров и управленцев возрастает, цели этих групп собственников будут сближаться и меньшее количество слияний, имеющих в своей основе иные мотивы, кроме как увеличение благосостояния акционеров, будут рассматриваться менеджерами. Исследования Льюэллена, Ламберта и Ларкера подтверждают эту идею для рынка корпоративного контроля США. Что касается британского рынка корпоративного контроля, Вейр [Weir, 1997] пришел к выводу о том, что исполнительные директора поглощаемых компаний имели существенно меньшую долю акций и опционов, чем исполнительные директора компаний, которые не были куплены в итоге. Это свидетельствует о том, что фирмы, в которых интересы менеджеров не совпадают с интересами акционеров, могут стать целевыми компаниями с большей степенью вероятности. Штульц [Stulz, 1981] пришел к выводу о том, что увеличение доли акций, принадлежащей менеджерам, вредит акционерам, поскольку менеджеры становятся более защищенными. В соответствии с результатами исследования Коша [Cosh, 2001] на более низком уровне управления возможно совпадение интересов собственников и менеджеров, в то время как на более высоком уровне управления поведение менеджеров не зависит от интересов собственников. Владение акциями также может привести к положительному результату и дружественной природе будущих сделок на рынке корпоративного контроля [O’Sullivan, Wong, 1998] и в то же время может снизить вероятность поглощения [Shivdasani, 1993], сигнализируя о том, что неэффективные менеджеры могут являться инициаторами сделок на рынке корпоративного контроля [Constantinou, Constantinou, 2003].

В отличие от приведенных ранее работ Лодерер и Мартин пришли к выводу, что менеджеры, которые владеют акциями в своей компании, могут вообще не иметь возможности влиять на корпоративные решения и могут быть вынуждены улучшать показатели фирмы в связи с увеличивающейся конкуренцией и повышением эффективности рынка корпоративного контроля. Это подтверждает результаты ранних исследований, которые также свидетельствовали о том, что показатели фирмы и доля менеджмента в капитале фирмы не связаны между собой [Demsetz, Lehn, 1985; Denis, Denis, 1994].

Важно отметить, что топ-менеджеры нанимают менеджеров среднего звена, стимулы для которых, безусловно, слабее, поскольку их работа, должность, заработная плата и премиальные зависят не только от них. Рынок труда для менеджеров формируется не только самим менеджментом и может быть эффективен только в том случае, если собственники могут отличить плохую работу менеджеров от хорошей и наказать их. Соответственно, если компания обладает монопольной властью, фондовый рынок неэффективен, акционеры не имеют общей стратегической линии поведения и плохо информированы, стимулы к максимизации благосостояния акционеров у менеджеров ослабевают [Davies, Lam, 2003].

Отметим, что чем меньше у собственников информации о том, как на самом деле работают менеджеры, тем больше стимулов сделать выплату компенсаций менеджерам как можно более отсроченной. Но чем выше вероятность угрозы враждебного поглощения, тем менее вероятно, что менеджеры согласятся на такие условия. Собственники могут использовать это в своих интересах и включить в устав компании оговорки об использовании защитных тактик в случае враждебного поглощения. Защитные тактики заставляют владельцев компании-покупателя торговаться с менеджерами целевой компании, повышая вероятность того, что менеджеры скоро получат какие-либо выплаты по опционам [Chakraborty, Baum, 1998]. Однако не стоит забывать и о том, что менеджеры, получающие большую часть компенсационного пакета опционами, более склонны к манипуляциям финансовыми показателями для того, чтобы увеличить текущую стоимость акций и размер 
своей компенсации (что, вероятнее всего, негативно скажется на долгосрочной стоимости компании) [Пирогов, Урюпин, 2007].

\section{Менеджмент компании и перераспределение корпоративного контроля: основные выводы}

В целом анализ результатов приведенных исследований позволяет сделать несколько групп выводов о том, как меняется эффективность работы менеджеров при перераспределении контроля и о различных способах стимулирования менеджеров.

Во-первых, существует несколько противоречивых точек зрения относительно того, связаны между собой показатели деятельности фирмы (а именно капитализация, как общепризнанная мера благосостояния акционеров компании) и качество менеджмента (то есть эффективность управления компанией в целом и персоналом этой компании на различных уровнях в частности):

1) участие менеджеров в акционерном капитале компании позволяет нивелировать агентский конфликт и, следовательно, повышает качество и эффективность работы менеджмента;

2) владение акциями может повлиять на независимое поведение членов советов директоров (особенно это касается неисполнительных директоров), что ведет к снижению качества управления, ухудшению показателей компании и неэффективности самого рынка корпоративного контроля как механизма мотивации менеджмента;

3) владение акциями не связано с качеством менеджмента и рыночными показателями компании [Constantinou, Constantinou, 2003].

В статье Байбуриной и Шустровой приведена классификация подходов к оценке взаимосвязи между качеством работы советов директоров и топ-менеджмента и результатами деятельности компаний, а также результаты собственного исследования авторов, проведенного на основе выборки, в которую попали крупнейшие российские компании из различных отраслей. Авторы статьи акцентируют внимание на том, что в определенной степени вознаграждение топ-менеджеров и совета директоров крупных российских компаний позволяет частично элиминировать конфликт интересов между менеджерами и акционерами. Соответственно, вознаграждение опосредованно, через механизм принятия решений топ-менеджментом и советом директоров, влияет на ожидания рынка, что, в свою очередь, отражается на рыночной стоимости компании в той степени, в какой это возможно [Байбурина, Шустрова, 2008].

В свете разгоревшихся в конце 2008 - начале 2009 гг. корпоративных скандалов в США и Европе вопрос об эффективности действий топ-менеджмента и различных механизмах мониторинга и управления персоналом компаний стоит особенно остро. Менеджеры American International Group (AIG) получили \$165 млн бонусов, хотя за последний год компания подешевела в 34 раза, получила убыток и держится на плаву только благодаря господдержке на десятки миллиардов [Хренников, Говорун, 2009]. Проблема актуальна и для России: в кризис многие компании запросили помощи у государства, при этом их топ-менеджеры получают солидные бонусы за, возможно, не слишком эффективную работу. Вне всяких сомнений, топ-менеджеры - особые люди, несущие огромную ответственность и риски, и, несмотря на кризис, людей необходимо мотивировать, но необходима жесткая и прозрачная зависимость между результатами работы и ее вознаграждением. Приведенные в статье примеры программ вознаграждения труда менеджеров (оплата акциями, опционами, привязка к долгосрочной рыночной стоимости компании) в большей или меньшей степени эффективны для привлечения (переманивания), удержания, мотивирования и поощрения сотрудников. Однако истинная цель программ вознаграждения - это повышение эффективности управления персоналом.

Любая характеристика, которая позволяет повысить качество менеджмента (и, следовательно, улучшить показатели фирмы), должна иметь положительное влияние на 
благосостояние акционеров, тогда как любая характеристика, которая ухудшает качество менеджмента, должна иметь отрицательный эффект.

Результаты исследований Константину свидетельствуют о том, что определенные характеристики советов директоров компании-покупателя и целевой компании оказывают существенное влияние на благосостояние акционеров компании-покупателя. Можно утверждать, что между благосостоянием и этими характеристиками существует связь (см. табл. 1), но гораздо более важно, что подтверждается гипотеза о том, что благосостояние акционеров компании-покупателя в большей степени зависит от характеристик совета директоров целевой компании, чем от характеристик собственного совета директоров [Constantinou, Constantinou, 2003].

Таблица 1.

Зависимость между благосостоянием акционеров компании-покупателяи характеристикой совета директоров целевой компании ${ }^{26}$

\begin{tabular}{|l|l|l|}
\hline $\begin{array}{l}\text { №№ } \\
\text { п/п }\end{array}$ & \multicolumn{1}{|l|}{ Характеристика совета директоров } & \multicolumn{1}{|c|}{ Зависимость } \\
\hline 1 & $\begin{array}{l}\text { Доля неисполнительных директоров в } \\
\text { совете }\end{array}$ & Вогнутая квадратичная зависимость \\
\hline 2 & Количество членов совета директоров & Выпуклая квадратичная зависимость \\
\hline 3. & $\begin{array}{l}\text { Количество компаний, в которых } \\
\text { неисполнительные директора также } \\
\text { принимают участие в советах директоров }\end{array}$ & Отрицательная линейная зависимость \\
\hline 4 & $\begin{array}{l}\text { Доля акций компании, принадлежащая } \\
\text { исполнительным директорам целевой } \\
\text { компании }\end{array}$ & $\begin{array}{l}\text { Положительная } \\
\text { зависимость }\end{array}$ \\
\hline
\end{tabular}

Эти характеристики можно считать статистически значимыми при объяснении изменений в благосостоянии акционеров компании-покупателя. Что касается совета директоров компании-покупателя, то только долю неисполнительных директоров в совете можно считать статистически значимым фактором, влияющим на изменение благосостояния акционеров компании-покупателя [Constantinou, Constantinou, 2003].

Тот факт, что акционеры компании-покупателя не принимают во внимание долю акций, которой владеют их собственные управленцы, размер совета директоров, членство в советах директоров других фирм при оценке будущего слияния не говорит о том, что это несущественные характеристики или о том, что эти характеристики не связаны с качеством собственного менеджмента. Это является лишь свидетельством того, что собственники компании-покупателя в целом удовлетворены качеством работы команды своих менеджеров. Однако им нужен показатель качества менеджмента, который связан с текущими решениями совета директоров (как, например, решения о слиянии / поглощении), и в качестве такого показателя они принимают количество неисполнительных директоров в совете. С другой стороны, акционеры компании-покупателя не слишком хорошо осведомлены об управленческих качествах менеджмента целевой компании и, следовательно, они пытаются оценить всю возможную информацию, какой только владеют о совете директоров целевой компании, для того чтобы выработать стратегию поведения [Constantinou, Constantinou, 2003].

Еще один из немаловажных результатов исследования Константину заключается в эмпирическом доказательстве исключительной эффективности института независимых советов директоров: именно такие советы приносят наибольшие выгоды акционерам при поглощении. Байбурина и Шустрова в своем исследовании также подтверждают, что

\footnotetext{
${ }^{26}$ Сост. по: [Constantinou, Constantinou, 2003].
} 
наличие независимых директоров в составе совета директоров крупных российских компаний обеспечивает более эффективные решения и сбалансированность интересов различных стейкхолдеров [Байбурина, Шустрова, 2008]. Оптимальная доля неисполнительных директоров (независимо от того, чей это совет - компании-покупателя или целевой компании), по их мнению, составляет 48\%. Можно с уверенностью утверждать, что и от исполнительных, и от неисполнительных директоров мы должны ожидать одинаково эффективных для собственников решений [Constantinou, Constantinou, 2003]. Это ставит под сомнение преимущество владения инсайдерской информацией и заставляет задуматься об эффективности существующих механизмов мониторинга, контроля и управления эффективностью действий топ-менеджмента компаний.

Вторая важная группа выводов касается тех механизмов, которые в большей или меньшей степени позволяют мотивировать менеджеров действовать в интересах владельцев бизнеса при слияниях и поглощениях. Безусловно, те, кто являются одновременно и владельцами, и сотрудниками организации, обладают большей преданностью делу и больше заинтересованы в успехе компании, а хороший управленческий компенсационный план должен обеспечивать такие стимулы для менеджеров, чтобы они осуществляли только те слияния, которые увеличивают благосостояние акционеров.

Каждый раз, когда встает вопрос о слиянии / поглощении, топ-менеджмент целевой компании оказывается перед выбором: либо торговаться с компанией-покупателем, ставя во главу угла свои личные интересы (чтобы не оказаться после завершения сделки на улице), либо торговаться, защищая интересы своих акционеров с целью получить максимально возможную цену за активы компании. В своем исследовании Л. Баргерон, и др. [Bargeron, Schlingemann, Stulz, Zutter, 2009] ${ }^{27}$ изучали факторы, которые оказывают влияние на увольнение топ-менеджеров целевых компаний после завершения слияния / поглощения, и то, насколько топ-менеджеры (целевой компании) могут повлиять на цену, уплачиваемую компанией-покупателем.

Хартселл и др. [Hartzell, Ofek, 2004] исследовали дружественные поглощения за период 1995-1997 гг. и пришли к выводу, что менеджеры целевых компаний получают значительные выгоды в результате сделок, и это неудивительно, поскольку топ-менеджерам, потерявшим свои посты в результате поглощений, будет достаточно сложно найти подобную работу в других компаниях [Agrawal, Walking, 1994]. Также Хартселл отмечает, что акционеры целевых компаний получают значительно меньшие выгоды (в сравнении с менеджерами целевых компаний) [Hartzell, Ofek, 2004].

Результаты исследования Л. Баргерона и др. свидетельствуют о том, что вероятность увольнения топ-менеджмента целевой компании возрастает в случаях, если:

1) компания-покупатель является публичной, а не частной;

2) целевая компания характеризуется неблагоприятными рыночными характеристиками;

3) доля акций, которыми владеют менеджеры целевой компании, невысока [Bargeron, Schlingemann, Stulz, Zutter, 2009].

Независимо от того, является ли компания-покупатель частной или публичной, Л. Баргерон и др. не находят подтверждения тому, что в случае, если компания-покупатель заплатит более низкую цену, топ-менеджмент целевой фирмы сохранит свои должности. Интересно также отметить, что цена акций целевой компании увеличивается в большей степени в связи с объявлением о том, что компанию приобретает частная фирма, чем о том, что топ-менеджмент целевой компании сохранит свои посты [Bargeron, Schlingemann, Stulz, Zutter, 2009]. Схожие результаты были получены и при изучении сделок на украинском рынке корпоративного контроля за период 2002-2006 гг.: основным результатом исследования, проведенного А. Муравьевым и др., стало подтверждение существования

\footnotetext{
${ }^{27}$ Исследование основывается на данных Securities Datta Company’s US Merger And Acquisition Database, были исследованы сделки за период 1994-2006 гг., совершенные в США, характеризующиеся 100\%-ным выкупом акций целевой компании и полностью оплаченные наличными денежными средствами.
} 
отрицательной зависимости между вероятностью увольнения топ-менеджмента компании и рыночными показателями фирмы [Muravyev, Bilyk, Grechniuk, 2009]. Гибсон, изучавший рынки корпоративного контроля Бразилии, Чили, Индии, Кореи, Малайзии, Мексики, Тайваня и Таиланда, также свидетельствует о том, что чем хуже рыночные показатели фирмы, тем выше вероятность увольнения топ-менеджмента целевой компании после завершения сделки [Gibson, 2003]. Исследование А. Муравьева и др. также подтверждает тот факт, что чем выше доля акций, которыми владеют менеджеры целевой компании, тем меньше вероятность их увольнения [Muravyev, Bilyk, Grechniuk, 2009].

Таким образом, хотелось бы еще раз подчеркнуть, что компенсации менеджерам, основанные на стоимости ценных бумаг компании, снижают стимулы к оппортунистическому поведению менеджеров [Shleifer, Summers, 1988; Baber, 1996] (особенно если их жалованье зависит от рыночной цены акций компании или часть жалования управляющие получают в виде акций / опционов на ценные бумаги компании ${ }^{28}$ ). Кроме того, степень доверия собственников информации, поставляемой рынком и собственным менеджментом, является главным стимулом для отложенных выплат управляющим (увеличения доли опционов в пакете их вознаграждения [Knoeber,1986]), a главный мотив для использования защитных тактик менеджерами целевых компаний - это желание повысить свое собственное благосостояние, а не благосостояние акционеров [Chakraborty, Baum, 2003].

\section{Список литературы}

1. Байбурина Э., Шустрова Е. Влияние вознаграждения топ-менеджмента и совета директоров на стоимость крупных российских компаний // Корпоративные финансы. - 2008. - № 4. - С.60-80.

2. Пирогов Н., Урюпин С. Блок «Корпоративное управление и корпоративные результаты: эмпирические доказательства на опыте развитых стран» // Корпоративные финансы. - 2007. - № 4. - С.59-60.

3. Хренников И., Говорун Ю. Премиальные из ниоткуда // Smart Money. - 2009. - № 10. - C.12-13.

4. Agrawal, A., Walking, R.A. (1994), Executive Careers And Compensation Surrounding Takeover Bids, Journal Of Finance, 49 (1994) 985-1014.

5. Baber, W. (1996), Investment Opportunities And The Structure Of Executive Compensation, Journal Of Accounting And Economics, 21 (1996) 297-318.

6. Baker, M., Wurgler, J. (2000), The Equity Share In New Issues And Aggregate Stock Returns, Journal Of Finance, 55 (2000) 2219-2258.

7. Baker, M., Wurgler, J. (2002), Market Timing And Capital Structure, Journal Of Finance, 57 (2002), 1-32.

8. Bargeron, L.L., Schlingemann, F.P., Stulz, R.M., Zutter, C.J. (2009), Do Target CEOs Sell Out Their Shareholders To Keep Their Job In A Market? NBER.

9. Bedard, K. (2001), Human Capital versus Signaling Model: University Access and High School Dropouts, Journal of Political Economy, 109 (2001) 749-775.

10. Bernhardt, D. (1995), Strategic Promotion and Compensation, Review of Economic Studies, 62 (1995) 315-339.

11. Chakraborty, A., Baum, C. (1998), Poison Pills, Optimal Contracting and Market for Corporate Control: Evidence From Fortune 500 Firms, International Journal of Finance, $10-3$ (1998) 1120-1138.

\footnotetext{
${ }^{28}$ В исследовании Э.Р. Байбуриной и Е.В. Шустровой мы также находим подтверждение тому, что вознаграждение топ-менеджеров и совета директоров крупных российских компаний в виде опционов на покупку акций ведет к сокращению разделения между собственником менеджером, то есть к снижению агентских издержек (как на примере их собственного исследования, так и а примерах исследований других авторов) [Байбурина, Шустрова, 2008].
} 
12. Charlambos Th.Constantinou and Costas Th.Constantinou. (2003), The Effect of Board Structure on Bidder-Shareholders' Wealth: Further Evidence From the UK Bidding Firms. ESRC Centre for Business Research: University of Cambridge.

13. Cosh, A., Guest, P., Hughes, A. (2001), Managerial Discretion and Takeover Performance. ESRC Centre for Business Research: University of Cambridge.

14. Cotter, J.F., Shivdasani, A., Zenner, A. (1997), Do Independent Directors Enhance Target Shareholders Wealth During Tender Offers? Journal of Financial Economics, 43 (1997) $195-218$.

15. Davies, H., Lam, P.-L. (2003), Managerial Economics. An Analysis of Business Issues. Prentice Hall.

16. Demsetz, H., Lehn, K. (1985), The Structure of Corporate Ownership: Causes and Consequences, Journal of Political Economy, 93(1985) 1155-1177.

17. Denis, D.J., Denis, D.K. (1994), Majority Owner-Managers and Organizational Efficiency, Journal of Corporate Finance, 1.1 (1994) 91-118.

18. Fama, E. (1980), Agency Problems and the Theory of the Firm, Journal of Political Economy, 88 (1980) 288-307.

19. Fama, E.F., Jensen, M.C. (1983a), Agency Problems and Residual Claims, Journal of Law and Economics, 26 (1983a) 327-349.

20. Fama, E.F., Jensen, M.C. (1983b), Separation of Ownership and Control, Journal of Law and Economics, 26 (1983b) 301-325.

21. Farber, H., Gibbons, R. (1996), Learning and Wage Dynamics, Quarterly Journal of Economics, 111 (1996) 1007-1047.

22. Gibbons, R., Katz, L. (1991), Layoffs and Lemons, Journal of Labor Economics, 9 (1991) $351-380$.

23. Gibson, S.M. (2003), Is Corporate Governance Ineffective In Emerging Markets? The Journal of Financial and Quantitative Analysis, 38 - 1 (2003) 231-250.

24. Hartzell, J., Ofek, E., Yermak, D. (2004) What's In It for Me? CEOs Whose Firms Are Acquired, Review Of Financial Studies, 17 (2004) 37-61.

25. Jensen, M. (1984), Takeovers: Folklore and Science, Harvard Business Review, (1984) $109-121$.

26. Jensen, M. (1986), Agency Costs Of Free Cash Flow, Corporate Finance and Takeovers, American Economic Review, (1986) 323-329.

27. Knoeber, C. (1986), Golden Parachutes, Shark Repellents and Hostile Tender Offers, American Economic Review, 76-1 (1986) 155-167.

28. Lang, K., Kropp, D. (1986), Human Capital versus Sorting: the Effects of Compulsory Attendance Laws, Quarterly Journal of Economics, 101 (1986) 609-624.

29. Manne, H. (1965), Mergers and the Market for Corporate Control, Journal of Political Economy, 73 (1965) 110-120.

30. Martin, K., McConnell, J. (1991), Corporate Performance, Corporate Takeovers, and Management Turnover, 46 (1991) 671-688.

31. Milgrom, P., Oster, S. (1987), Job Discrimination, Market Forces and the Invisibility Hypothesis, Quarterly Journal of Economics, 102 (1987) 453-476.

32. Modigliani, F., Miller, M.H. (1958), The Cost of Capital, Corporate Finance And the Theory of Investments, American Economic Review, 48 (1958) 261-297.

33. Morck, R., Shleifer, A., Vishny, R. (1988), Management Ownership And Market Valuation: An Empirical Analysis, Journal Of Financial Economics, 20 (1988) 293-316.

34. Muravyev, A., Bilyk, O., Grechniuk, B. (2009), Firm Performance And Managerial Turnover: The Case Of Ukraine. University Library Of Munich, Germany.

35. Myers, S.C., Majluf, N. (1984), Corporate Financing And Investment Decisions When Firms Have Information That Investors Do Not Have, Journal Of Financial Economics, 6 (1984) $187-221$.

36. O'Sullivan N. (2000), Managers as Monitors: An Analysis of the Non-Executive Role of 
Senior Executives in UK Companies, British Journal of Management, 10 (2000) 17-29.

37. O'Sullivan, N., Wong, P. (1998), The Impact of Board Composition and Ownership On the Nature and Outcomes of UK Takeovers, Corporate Governance: An International Review, 2, 6 (1998) 92-100.

38. Riley, J. (1979), Testing the Educational Screening Hypothesis, Journal of Political Economy, 87 (1979) 227-252.

39. Roll, R. (1986), The Hubris Hypothesis of Corporate Takeovers, Journal of Business, 35 (1986) 197-216.

40. Shapiro, C., Stiglitz, J. (1984), Equilibrium Unemployment as a Worker Discipline Device, American Economic Review, 74 (1984) 433-444.

41. Shivdasani, A. (1993), Board Composition, Ownership Structure and Hostile Takeovers, Journal of Accounting and Economics, 16 (1993) 167-198.

42. Shleifer, A., Summers, L. (1988), Breach Of Trust In Hostile Takeovers, in Auerbach A. Corporate Takeovers: Causes And Consequence. Chicago University Press.

43. Shleifer, A., Vishny, R. (2001), Stock Market Driven Acquisitions. NBER.

44. Shleifer, A., Vishny, R. (1988), Value Maximization And The Acquisition Process, Journal Of Economic Perspectives, 2 (1988).

45. Spence, A.M. (2001), Signaling In Retrospect And The Informational Structure Of Markets, Prize Lecture. December 8, 2001. Stanford Business School, Stanford University.

46. Stein, J. (1988), Takeover Threats And Managerial Myopia, Journal Of Political Economy, 96 (1988) 61-80.

47. Stein, J. (1989), Efficient Capital Markets, Inefficient Firms: A Model Of Myopic Corporate Behavior, Quarterly Journal Of Economics, 104 (1989) 655-669.

48. Stein, J. (1995), Rational Capital Budgeting In An Irrational World, Journal Of Business, 69 (1995) 429-455.

49. Stulz, R. (1981), On the Effects of Barriers to International Investment, Journal of Finance, 36 (1981) 923-934.

50. Waldman, M. (1984), Job Assignments, Signaling and Efficiency, Rand Journal of Economics, 15 (1984) 255-267.

51. Weir, C. (1997), Corporate Governance, Performance and Takeovers: an Empirical Analysis, Applied Economics, 29 (1997) 1465-1475.

52. Yermack, D. (1996), Higher Market Valuation of Companies with Small Board of Directors, Journal of Financial Economics, 40 (1996) 185-211. 